\title{
Entre influencia ilustrada europea y necesidades de un espacio periférico: el Consulado de Comercio de Buenos Aires como ámbito de experimentación y difusión de la Economía Política a fines del siglo XVIII
}

Between European Enlightenment influence and the needs of a peripheral space: the Consulate of Commerce of
Buenos Aires as a field of experimentation and diffusion of the Political Economy at the end of the 18th century

Adriana N. Milano

Universidad Nacional de Rosario, Argentina

adria_milano@yahoo.com.ar

\section{RESUMEN:}

Este trabajo parte de la importancia de los consulados de comercio en el mundo hispanoamericano del siglo XVIII. El propósito es evaluar el rol del Consulado de Comercio de Buenos Aires, entre el discurso ilustrado que comenzaba a difundirse en el Río de la Plata y una realidad local que exigía la resolución de problemas cotidianos propios de un espacio en construcción con necesidades puntuales diferentes de las europeas. Para ello, se realiza una comparación entre las reflexiones de Manuel Belgrano que circularon por la institución y temas concretos que el Consulado atendió en los últimos años del siglo XVIII para demostrar su intención de adherir a lineamientos de la Economía Política dieciochesca.

Palabras Clave: Consulados de comercio, Ilustración, Sociedades Económicas, Ociosidad, Río de la Plata.

\section{Abstract:}

This work is based on the importance of the consulates of commerce in the Hispanic-American world of the 18th century. The purpose is to evaluate the role of the Consulate of Commerce of Buenos Aires between the Enlightenment discourse that began to spread in the Río de la Plata and a local reality that demanded the resolution of everyday problems typical of a space under construction with specific needs different from the European. So as to achieve this, a comparison is made between the reflections of Manuel Belgrano that circulated through the institution and the specific issues that the Consulate attended in the last years of the 18th century, to demonstrate its intention to adhere to the guidelines of the eighteenth-century Political Economy.

KEYWORDS: Consulates of commerce, Enlightenment, Economic Societies, Idleness, Río de la Plata.

\section{INTRODUCCIÓN}

El consulado de Comercio de Buenos Aires, creado en 1794, fue apreciado por Annick Lémperière como el primer espacio para el despliegue de prácticas y producciones ilustradas, situación que equiparó a la existente para el Consulado de Santiago de Chile reflejo de la distancia cultural que separaba a los territorios sureños de América de otros más avanzados, como Nueva España, que desde tiempo antes contaron con otras alternativas para la circulación de ideas (2008, p. 257). La prensa como forma alternativa de difusión de reflexiones y debates apareció en Buenos Aires, a comienzos del siglo XIX, de manera tardía en comparación con Europa u otras ciudades americanas como México, Lima o La Habana (Calvo, 2008). Más allá del caso rioplatense, los consulados americanos en general se convirtieron entonces en núcleos de sociabilidad que convocaron a las elites donde se dirimían cuestiones prácticas, se construían redes y se difundían ideas, además de convertirse en instituciones para la aplicación de justicia en cuestiones comerciales.

Desde inicios del siglo XVIII, luego de la muerte de Carlos II, la llegada de la dinastía de los borbones y su política de restaurar el predominio de la monarquía con la superación de una situación diagnosticada desde el siglo anterior como de paulatina decadencia- supuso la implementación de todo tipo de medidas, en un contexto de difusión de nuevas ideas, prácticas y organismos. El período comprendido entre los años 
1680 y 1740 significó para la Monarquía Hispánica tener que padecer los rigores de su pérdida de hegemonía y un notorio retroceso material. Esta situación estuvo acompañada por la aparición de propuestas creativas para lograr una necesaria "mudanza de estilo". Con ello se buscaba hacer frente a nuevas realidades y alcanzar una auténtica reconfiguración de la Monarquía en su conjunto, como un cuerpo dentro del escenario de la modernidad, que, en definitiva, aún estaba con vida (Fernández Albaladejo, 2015, 2009). Las ideas para el cambio se gestaron tanto desde el interior de la Monarquía como desde fuera. Si desde esta última perspectiva llegó a plantearse su incapacidad para seguir un modelo de desarrollo y nuevo orden como el inglés, anclado en la cultura del comercio, desde el interior se barajaron alternativas de reactivación más optimistas, que también veían en el comercio una vía para el progreso (Botella Ordinas, 2015). De ese modo, para mediados del siglo XVIII un nuevo discurso imperial tomaría paulatinamente forma en una matriz intelectual donde partidarios de la ciencia del comercio ilustrada perfilaron un sistema en el que la monarquía compuesta debía convertirse en un imperio comercial capaz de encauzar el mercado colonial en beneficio propio (Tavárez Simó, 2015). En ese contexto en que recuperar el antiguo esplendor comercial se erige como opción salvadora, los consulados cobrarán un rol revalorizado y renovado.

Desde el punto de vista de las herramientas institucionales, los consulados de comercio fueron entonces espacios claves en la mencionada remodelación emprendida a partir del siglo XVIII. Si bien no eran entidades novedosas, la segunda mitad de ese siglo fue el lapso de mayor aparición de éstos en ciudades americanas, reflejo de la nueva política borbónica (Souto Mantecón, 1990). A nivel funcional, en su origen constituyeron un medio para negociar el apoyo entre corporaciones mercantiles y la Corona, pero en el siglo XVIII perdieron su autonomía jurídica para convertirse en concesiones e instrumentos del poder real (Cruz Barney, 2002).

Los consulados ejercieron roles articuladores de relaciones sociales, fueron espacios de confrontación de intereses y de acción mancomunada con distintos fines. Tal fue el caso del primer consulado americano, el de la ciudad de México, pilar de la administración colonial para la recaudación fiscal, y de la intermediación financiera con la Corona, además de constituir un grupo cerrado con intereses comunes que exigían acción coordinada de sus dos grupos hegemónicos - mineros y comerciantes-, que se sucedieron en su gobierno interno y tuvieron luego lugar destacado en el movimiento independentista del siglo XIX (Del Valle Pavón, 2015).

Otro caso emblemático fue el consulado de Cartagena en el virreinato de Nueva Granada, creado en 1795, que además de entidad comercial se constituyó en un arma política que permitió a los comerciantes cartageneros, por sobre los de Santa Fe de Bogotá, complementar su supremacía y poder económico para pasar, de una actuación a nivel local, al manejo de un poder regional (Cuño Bonito, 2009).

En el caso del consulado de Lima, creado en 1613, cuando en el último cuarto del siglo XVIII la elite mercantil limeña -los almaceneros o cargadores- entró en crisis a raíz de las reformas borbónicas, el cuerpo consular se convirtió en portavoz del sector y logró que algunas decisiones de las autoridades virreinales les fueran favorables (Laserna Gaitán, 1995). Se trató de una institución en la que la elite limeña estuvo en estrecho contacto con su par norteña de Piura -conformada por comerciantes- vinculada con Lima por la relación de los piuranos con los grandes apellidos limeños ligados al comercio a gran escala, y por el interés con que los consiliarios limeños veían a esa provincia, preocupándose por su control comercial (Hernández García, 2013). Tanto el consulado de Lima como el de México supieron erigirse como verdaderos centros de poder. Cristina Mazzeo analizó incluso la dependencia de los estados posteriores, derivados de los virreinatos de Nueva España y del Perú en el paso al período republicano, problema que evidenció a partir de las finanzas de las nuevas entidades políticas, y, puntualmente, el papel de los comerciantes como donantes y prestamistas en los consulados de México y Lima, convertidos en gestores de un poderoso mecanismo de financiación. Mazzeo puso a la luz la debilidad institucional de los estados mexicanos y peruanos por su vinculación con agiotistas o comerciantes, quienes, al ritmo de los cambios provocados por el Reglamento de Libre Comercio 
y la creación de nuevos consulados, se perfilaron como grupos fuertes, dotados de capacidad para negociar con el poder (Mazzeo, 2012).

En el sur americano, el consulado de comercio chileno, creado en 1795 -al año siguiente que el de Buenos Aires-, a fines del siglo XVIII reflejó la influencia en su seno de comerciantes españoles con presencia sobre todo en Santiago y en el puerto cercano de Valparaíso. El tribunal del consulado de Santiago facilitó a los comerciantes locales una organización política común frente a las autoridades y se convirtió en un órgano colegiado de fomento y gestión económica, además de tribunal para su sector. Los comerciantes originarios de Cantabria y los "montañeses" de Burgos, junto a los de provincias vascas y de Navarra, supieron articularse en el interior del consulado por diferentes vínculos, que incluyen los de tipo familiar y, en especial, los de paisanaje (Betancourt Castillo, 2012).

Los consulados conformaron así núcleos complejos que articulaban relaciones variadas y ejercían influencia en su entorno político, económico y social. Constituyeron espacios de sociabilidad y poder con características diferentes según las distintas ciudades virreinales en las que se erigieron.

En esa coyuntura favorable para el surgimiento de consulados en América, la ciudad de Buenos Aires logró la apertura del suyo en 1794 y se convirtió en la primera ciudad al sur del Virreinato en lograr tal concesión por parte de la monarquía hispánica.

\section{El Real Tribunal del Consulado de Buenos Aires. Sociabilidad e integración INTERJURISDICCIONAL}

Las relaciones de la elite bonaerense con el consulado de comercio de Buenos Aires resultaron siempre estrechas y la historiografía ha dado cuenta de los diferentes aspectos de consolidación de grupos mercantiles y hacendados, sus estrategias de acumulación, las relaciones entre pares y su presencia dentro del Consulado entre muchos otros aspectos a lo largo de los siglos XVIII y primeras décadas del XIX. Dichos trabajos permiten contar con un sólido contexto para enriquecer cualquier reflexión que involucre el período de funcionamiento del Consulado de 1794 a 1821 y las situaciones que a partir de él se derivaron (Socolow, 1991; Harispe, 2012; Fradkin, 2014; Hora, 2014).

El Real Tribunal del Consulado de Buenos Aires se creó por cédula real el 30 de enero de 1794 y los motivos de su erección se presentaban en el documento oficial redactado durante el reinado de Carlos IV. Noemí del Carmen Bistué y Alba María Acevedo remarcaron que la finalidad era la protección del tráfico y decisión "breve y sumaria" sobre pleitos mercantiles, y, de hecho, significó el reemplazo de procesos lentos y engorrosos de resolución de conflictos mercantiles -otrora llevados adelante por jueces ordinarios- por otros breves y poco costosos, en los que la justicia era administrada por los propios pares (2015, p. 388). El aumento del comercio y las salidas hacia diferentes puertos superaban las posibilidades operativas de los únicos dos consulados, de Lima y México, para toda América. La cédula dejaba constancia del asesoramiento encomendado por Carlos IV a sus "ministros de Estado y de despacho", y de la evaluación y confección de informes para decidir "lo que más conviniese al bien y prosperidad del comercio". Además de dichas instancias, el Consejo de Estado había evaluado el informe local presentado por el "cuerpo de comercio" de la ciudad de Buenos Aires, avalado por el virrey Arredondo. El objetivo de la institución se establecía de manera expresa: "la más breve y fácil administración de justicia en los pleitos mercantiles y la protección y fomento del comercio en todos sus ramos". Para la resolución de pleitos y diferencias se tomaban como referencia las ordenanzas del Consulado de Bilbao, y de manera supletoria las Leyes de Indias o las leyes de Castilla (AGNC, 30/01/1794, pp. 2-4).

El contexto de su creación coincidió con circunstancias decisivas para el futuro de la ciudad y el espacio rioplatense. Después de la real cédula de libre comercio de 1778 se aunaron esfuerzos para la habilitación de los puertos de Buenos Aires y Montevideo junto a la creación de un consulado, gestiones que inició el virrey Arredondo secundado por la Real Audiencia. Los conflictos con Portugal por las tierras de la Banda Oriental 
y Río Grande, junto a la entrada inglesa en Malvinas, condujeron a la Corona a intentos por controlar la Banda Oriental y acotar el poder naval inglés asentado comercialmente desde 1713 con el Tratado de Asiento. Las medidas incluyeron los tratados de Permuta (1750), San Ildefonso (1777) y el de Pardo (1778), que concluyeron los conflictos limítrofes con Portugal y un apostadero naval en Montevideo para vigilar costas patagónicas y Malvinas a partir de 1776. La creación del virreinato del Río de la Plata en 1776 fue otro hito que elevó a Buenos Aires a cabeza jurisdiccional y puerto habilitado para comercio de ultramar. En 1774 se le permitió comerciar con Chile y Perú; en 1777 se autorizaron transacciones en todo el nuevo virreinato por auto de libre internación. En 1778 con el reglamento de libre comercio se habilitó su puerto y se fundó la Real Aduana, institución de gran significación por el rol que la fiscalidad tendría tanto en el funcionamiento de los dominios españoles, como en su proyección posterior en los procesos de formación de los Estados nación del siglo XIX latinoamericano (Vaccani, 2015).

Con la real cédula de libertad de comercio de esclavos se fomentó la entrada de navíos, con su posterior salida, cargados de productos locales (Suárez-Tornay, 2003). En ese contexto se erigió el consulado de Buenos Aires en un momento en que el circuito económico comenzaba a concentrarse -en especial a partir de la autorización del comercio extranjero de 1795 con la entrada del Río de la Plata en el comercio internacionalen manos de comerciantes y hacendados del litoral, y tuvo eje en los puertos de Buenos Aires y Montevideo (Crespi y Salles, 2002).

El análisis pionero del consulado bonaerense de Germán Tjarks fijó los antecedentes de la institución en el marco de la política comercial española en el Río de la Plata, sus implicancias para la organización de la justicia mercantil, la significación del organismo para el comercio interior y exterior rioplatense, su rol en la política portuaria y sus aportes para la infraestructura en caminos y puentes; el fomento de la industria, la agricultura, artes y en particular para el estudio de las ciencias exactas, el dibujo y el desarrollo de la Universidad de Buenos Aires (Tjarks, 1962). Los últimos objetivos mencionados lo conectaban con el rol que las Sociedades Económicas cumplían en la Península e interesan aquí en particular por el impulso al progreso que en especial su secretario, Manuel Belgrano, preveía lograr a partir del Consulado, emulando las funciones pedagógicas y de difusión de las Sociedades Económicas europeas.

El Consulado de Buenos Aires derivó en varias implicancias que lo conectaron con su entorno. Con respecto a las relaciones de poder vinculadas a la elite bonaerense de los siglos XVIII y XIX, Benjamín Rodríguez señaló que las tratativas para la creación de un consulado en Buenos Aires fueron resultado de la gestión del grupo comercial dominante en esa ciudad. Esta situación puso en evidencia las estrategias de esos actores en torno al ejercicio de una justicia de tipo corporativa, que afectaba la aplicación de la justicia a partir de una serie de prácticas y connivencias que eran producto de la cercanía entre demandantes, demandados y jueces $(2013$, p. 9). Por otra parte, los consulados también pueden verse como la forma en que la Corona enfrentó su propia debilidad en América, creando estos instrumentos institucionales y promoviendo la formación de cuerpos locales para negociar los términos del vínculo en beneficio de la Corona y de los grupos que conformaban esos núcleos locales (Kraselsky, 2011).

Según Javier Kraselsky el Consulado redundó en ventajas para la monarquía que se beneficiaba de la corporización de los sectores de poder para negociar beneficios y mutuas contraprestaciones (2007, p. 167). Tal situación no significó, empero, que el sector comerciante fuese homogéneo; muy por el contrario, lejos de toda uniformidad, existía en su interior toda una serie de facciones o sectores heterogéneos (Kraselsky, 2005).

La pertenencia a la institución constituía una marca de prestigio entre los comerciantes bonaerenses. Nora Siegrist señaló que, del mismo modo participar en la Orden Tercera de San Francisco había sido símbolo de distinción desde el último cuarto del siglo XVIII, el Consulado les servía ahora como espacio social para proyectar sus actividades cotidianas regionales y ultramarinas. Tanto para los cargos en Buenos Aires como para las diputaciones en las distintas ciudades, la elección de candidatos recayó sobre los vecinos comerciantes de las familias más reconocidas. En Buenos Aires, apellidos como Anchorena, Martínez de Hoz, 
Lezica y muchos otros encumbrados participaron de sus sesiones. Lo mismo se corrobora si se observan las diputaciones (2006, p. 7).

Desde el punto de vista de la sociabilidad y los circuitos intelectuales del siglo XVIII, se buscó dilucidar cómo los consulados se vincularon con los círculos de la Ilustración y llegaron a ser concebidos como fuentes de información para la discusión y difusión de las nuevas ideas ilustradas (Navallo, 2010). Desde esta perspectiva, la labor de Manuel Belgrano desde su cargo como secretario del consulado fue valorada como una herramienta para predicar las nuevas ideas ilustradas, aunque Fernando Jumar planteó interrogantes acerca de la verdadera influencia de su discurso en el ámbito de la institución (2007, p. 9). Belgrano es un ejemplo de formación de la elite colonial rioplatense -vinculado a la introducción de novedades de la economía política-, en primer lugar, por su paso por el Real Colegio de San Carlos (1783-1786), y luego -entre 1786-1788- por su actividad en la Universidad de Salamanca (Pastore y Calvo, 2000). El rol del comercio en el imaginario de una parte de la población rioplatense del siglo XVIII y el interés por crecer en habilidades para su desarrollo se comprueban en unas palabras rescatadas por Jorge Gelman del padre de Manuel Belgrano, Domingo Belgrano Pérez, quien procuró que dos de sus hijos, Francisco y Manuel, fueran a España "para que se instruyer[a]n en el comercio, se matriculen en él y regresen con mercaderías a estos Reynos". Manuel, sin embargo, estudió derecho en lugar de comercio y retornó a Buenos Aires como secretario del Consulado (1996, p.143).

En síntesis, podemos ver al Consulado de Buenos Aires como una institución de múltiples facetas, similar a tantos otros organismos virreinales, que se utilizaban como instrumento para fomentar los intereses particulares del sector mercantil. Los comerciantes, por su parte, buscaron canalizar sus demandas de manera inorgánica desde la primera mitad del siglo XVIII y de forma orgánica a partir de 1779 con las Juntas de Comercio. En 1797 la Corona fijó que hacendados y comerciantes se alternaran en su conducción, por lo cual pasaron a representarse los intereses locales del comercio y de la producción en una institución que, entre otras cuestiones, servía para proteger los intereses particulares de cada grupo (Jumar y Kraselsky, 2007).

En tal contexto, la figura de Manuel Belgrano como secretario vitalicio del organismo resulta fundamental para observar de qué modo en aquellos últimos años del siglo XVIII las ideas político-económicas de la Ilustración europea se recuperaban y se resignificaban -en una concepción particular ajustada al Río de la Plata- en una institución que permitió canalizar conceptos e inquietudes como aporte a la construcción de una esfera pública en tiempos anteriores a la aparición de la prensa como forma alternativa de difusión.

\section{LAS PREOCUPACIONES DE LA ECONOMÍA POLÍTICA EUROPEA Y EL INTENTO DE ADAPTACIÓN} AL CONTEXTO LOCAL

Múltiples variables y consideraciones provenientes de pensadores preocupados por las condiciones europeas en general e hispánicas en particular circulaban en la península ibérica como diferentes intentos por resolver cuestiones inmersas en un campo semántico amplio que involucraba discusiones y propuestas acerca del progreso, la ociosidad, la educación y, en última instancia, la felicidad como finalidad máxima de la monarquía hispánica, entre otros conceptos asociados (Milano, 2017). Una pléyade de intelectuales, muchos de ellos funcionarios asesores de la Corona, discutieron la realidad económica, política y social imperante en la Península y sus dominios durante el siglo XVIII. Nombres como Gaspar Melchor de Jovellanos y Pedro Rodríguez de Campomanes, sin duda los más difundidos, junto a muchos otros como Jerónimo Uztáriz, Francisco de Cabarrús, Cándido María Trigueros, Francisco Romá y Rosell, Pascual Vallejo, Gregorio Mayans, Pablo de Olavide, Bernardo Ward, fray Jerónimo Feijoo, León de Arroyal, José Moñino y Redondo (Conde de Floridablanca) o José Climent -solo por mencionar a algunos de los tantos a quienes Vicente Llombart Rosa ha clasificado en tres generaciones, cada una con características diferentes en su elaboración teórica- se dedicaron a revisar el atraso económico español (2006, pp. 95-113). Tampoco debe olvidarse a quienes desde el exterior discutían la realidad hispana y su situación frente a los cambios 
globales que se producían en la modernidad europea; autores como François Fénelon en su memoria, $L a$ guerre de la sucesión d'Espagne, de 1701, o Montesquieu, años más tarde en su Pensées, son muestras de ello (Fernández Albaladejo, 2015)

Para el Río de la Plata, José Carlos Chiaramonte subrayó la presencia -en la literatura ilustrada anterior a la independencia- del documento de tema económico bajo formatos varios, como artículos periodísticos, peticiones a las autoridades o memorias institucionales. Tales escritos estaban atravesados en algún aspecto por influencias francesas fisiócratas o neomercantilistas españolas y aún por el neomercantilismo de los ilustrados napolitanos, como Antonio Genovesi, Galiani o Gaetano Filangieri. Las Lezioni di commercio de Genovesi fueron casi literalmente incluidas en las Representaciones de agricultores, de 1793, o hacendados de 1794. Neomercantilismo italiano y español (Campomanes o Jovellanos, por ejemplo) representaban una opción de reflexión para los rioplatenses interesados en reformas viables dentro de los dominios de la monarquía hispana. No obstante, la influencia inglesa también estuvo presente, aunque sus doctrinas fuesen tomadas con indicación expresa de readaptarlas a las circunstancias locales, como era el caso de Adam Smith. Recién en la segunda década del siglo XIX, con la inauguración de la cátedra de Economía en la Universidad de Buenos Aires (en 1823), la "ortodoxia smithiana" comenzó a difundirse como enseñanza. Lo mismo ocurrió en la prensa oficial bonaerense durante el período de gobierno rivadaviano y primer período rosista. No obstante, aclara Chiaramonte, la influencia neomercantilista italiana en las provincias del Litoral se mantendría opuesta a la política de Buenos Aires (1989, p. 73). De hecho, Domingo Faustino Sarmiento señaló, sobre finales de la primera década del siglo XIX, que la adhesión a diferentes ideas económicas era un ingrediente más en la separación y antagonismo entre Buenos Aires y el interior. La influencia utilitarista del filósofo inglés Jeremy Bentham, además de James Mill, Destutt de Tracy y Dominique de Pradt en la formación de Bernardino Rivadavia pueden verse puntualmente durante su gestión en la "Feliz experiencia" (1821-1824) del gobierno porteño de Martín Rodríguez, considerada una opción para el progreso dentro del liberalismo moderno en boga (Gallo, 2001, 2002). El utilitarismo, junto al sensualismo y la Idéologie serían las alternativas que se sumaron en la circulación de ideas en la primera mitad del siglo XIX, y ampliaron el espectro intelectual para una nueva "cultura literaria", posible gracias a la Ley de Prensa, que favoreció la emergencia de mayor número de publicaciones periódicas, y enriqueció la formación de la esfera pública rioplatense (Myers, 1998).

La circulación de todas estas ideas representó un cambio intelectual y cultural profundo, enmarcado en un proceso de transición dentro de la América hispana desde una cultura barroca hacia otra ilustrada, cuyos primeros signos de cambio se harían notorios a partir de mediados del siglo XVIII con pleno impulso durante las reformas borbónicas, iniciadas con Carlos III y continuadas por Carlos IV. Ello estaría asociado a otro fenómeno: la conformación paulatina de una esfera pública, debida al aumento en la densidad de las tramas de sociabilidad en Iberoamérica; a las sociedades económicas, los consulados y luego a la prensa como ámbitos para la difusión y la reflexión, que aportaron a la gestación de un pensador novedoso que Jorge Myers identificó como el letrado patriota o escritor ilustrado (Myers, 2008). Respecto de los escritos ilustrados rioplatenses, Chiaramonte señaló su particularidad de propiciar en general el logro de mejores condiciones para la circulación mercantil sin lesionar los ordenamientos del fisco hispano. Por otra parte, buscaban aleccionar desde una perspectiva pedagógica sobre novedades técnicas para la agricultura y efectuar una crítica moralizante hacia aquellas conductas que impedían el logro de la felicidad general con la difusión del conocimiento racional (1989, p. 74).

El Consulado de Buenos Aires sería entonces, dentro de este contexto de novedades y de sociabilidades, un espacio para la circulación y la conformación de la esfera pública rioplatense, antes de que la prensa se manifestara con la aparición, a instancias de Belgrano, del Telégrafo Mercantil desde 1801, seguido entre 1802 y 1807 por el Semanario de Agricultura, industria y comercio, a cargo de Hipólito Vieytes, como publicaciones pioneras editadas con el beneplácito del Consulado (Martínez, 2009). 
Por otro lado, el Consulado es un espacio ideal para observar el caso de Manuel Belgrano en su relación con las pretensiones de instrumentalizar ideas ilustradas en el contexto bonaerense dentro del esquema mercantilista borbónico. Sus memorias anuales del Consulado -como secretario de la institución- son documentos útiles para analizar las medidas que por intermedio de la institución consular ansiaba introducir y poner en práctica, las cuales eran propias de un hombre que por su formación europea perseguía extender a su lugar de actuación las novedades en boga en las discusiones sobre economía política (Lafit, 2017). Pero además, permite profundizar en las inflexiones que Belgrano experimentó a lo largo de su vida como intelectual, súbdito, y militar, también durante su participación en la etapa virreinal y frente al proceso revolucionario: un funcionario de la Corona pero además hijo de Domingo Belgrano Pérez (Peri) -uno de los comerciantes más prósperos de la elite bonaerense-, que luego estuvo involucrado política y militarmente en las guerras de Independencia (Gelman, 1996).

Como señalara Javier Kraselsky, su redacción de las Memorias muestra una impronta liberal, tomado este calificativo con la acepción remarcada por Fabio Wasserman para caracterizar a quienes, en el marco de las reformas borbónicas, promovían la felicidad pública sin asociarse con el liberalismo como corriente que se extendió gradualmente a partir de la revolución rioplatense (2008, p. 68). El trabajo de Kraselsky muestra la formación de Belgrano en el pensamiento ilustrado francés, británico y español; un hombre que reconoce en su autobiografía la influencia de las ideas liberales de las revoluciones francesa y americana, aunque no sin ambigüedades como la de defender el fomento al culto teísta. Su actuación en el Consulado refleja un período en la vida de un hombre de la elite ilustrada porteña que continuaría luego su reflexión en la prensa y que formaba parte de un grupo local cuyos intereses defendía al igual que los de la Corona, como miembro de una institución monárquica. Kraselsky remarcó las variaciones en el desarrollo del pensamiento de Belgrano a lo largo de las diferentes Memorias. En sus enunciados defendió primero a la agricultura como el verdadero destino del hombre, de la que dependían las demás actividades, incluido el comercio; perjudicial a largo plazo si era ejercido como actividad principal. Luego, en 1798 celebraría la decisión real de unir a comerciantes y hacendados en el seno consular, y en 1802 abogaría por el establecimiento de curtiembres para el fomento de los cueros como la mayor riqueza local. A su vez, identificó a los hacendados como actores claves de la economía. Para 1809, producido ya el quiebre del poder real, acusaba a los ingleses y al contrabando local de perjudicar los intereses de "nuestra Madre Patria" y a la necesaria libertad de comercio. En síntesis, como puede rescatarse de la citada investigación el Consulado permite ver a la figura de Belgrano como un agente leal a la Monarquía que apoyaba la libertad de comercio -con la unión de hacendados y comerciantespara el fomento de las producciones locales y promovía las reformas borbónicas ideadas desde el reinado de Carlos III sin buscar una ruptura ideológica con el Antiguo Régimen, sino apenas una modernización de las estructuras monárquicas. Durante el período revolucionario intentaría evitar la desunión junto a la autonomía rioplatense, pero en una lucha que aún no se libraba contra las instituciones monárquicas. Esto se dio hasta que a partir de 1816 comenzaría una nueva época de guerras por la Independencia (2010, pp. 131-144).

Si se analizan las Memorias, es evidente que, como muchos escritos europeos, reflejaban preocupación por el ocio -sobre todo en las mujeres-como problema social y económico, al punto que puede considerarse que la ociosidad u "holgazanería" constituyen el eje discursivo de las memorias aquí analizadas, correspondientes a los últimos años de la centuria: 1796, 1797 y 1798. Son conocidas de hecho las reflexiones contemporáneas al respecto en buena parte de los pensadores ilustrados del siglo XVIII. Los escritos de Campomanes, Arriquibar, Dánvila y Villarrasa, Genovesi o Jovellanos, por mencionar algunos, daban cuenta de la transformación del tema en una variable a evaluar y manejar en el campo de la economía política ${ }^{\mathrm{i}}$.

En el Río de la Plata, Belgrano proponía en sus memorias a las Sociedades Económicas de Amigos del País como ejemplos de pedagogía y prácticas para el reordenamiento social, dignas de ser imitadas. Si bien la dinámica de las Sociedades no siempre estuvo a la altura de sus ambiciones, la historiografía actual tiende a considerar su función como positiva en general (Bolufer Peruga, 2011). Para Beatriz Ruibal, la 
admiración de Belgrano por estas Sociedades se observaba no solo en su interés por impulsar actividades similares a las emprendidas por éstas, sino también en seguirlas en sus propuestas modernizadoras de comportamiento. Para la lectura de su memoria de 1796, por ejemplo, previó emularlas en su manera de reformular cuestiones de etiqueta indicando, como aquellas, que los asistentes evitasen el orden corporativo y se sentasen indistintamente en cualquier lugar. Esto constituía un indicio de su interés por adecuarse a las nuevas pautas de sociabilidad ilustrada en la Península (2000, p. 430).

Sociedades Económicas, ocio y trabajo femenino son así tres elementos rescatados e interrelacionados por Belgrano. En 1796 veía a la población de Buenos Aires infestada por "hombres ociosos en la miseria y desnudez": infinidad de familias en la miseria sin estar ocupadas en oficios útiles para lograr mayores comodidades en la vida. Le preocupaba, sobre todo, la "multitud de criaturas" que llegaban a la pubertad ejerciendo solo el ocio y atendidas en todas sus necesidades (Belgrano 1796, p. 75). Al igual que en Europa encontraba en el premio el medio para estimular el esfuerzo personal por emulación de resultados puntuales que el Consulado debía dar a conocer y premiar: "el premio y el honor" ahuyentarían la holgazanería del Virreinato, reiteraba en 1798. Reconocía en este aspecto la influencia de las ideas de Pedro Rodríguez de Campomanes (Belgrano, 1796, p. 111). La preocupación por el ocio era general en América y, al igual que en las Sociedades Económicas, el premio se veía como el vector que promovería el adelanto y el interés por el progreso (Bottarini, 2010). Ello se complementaba con la necesidad de control y policía, en boga en el pensamiento ilustrado europeo, que tuvo su resonancia en la reflexión ilustrada rioplatense de fines del siglo XVIII (Zamora, 2014).

La cuestión femenina no quedó en una simple exposición teórica sino que la insertaba en una propuesta de programa, a ejecutar a través del Consulado, de producción local de hilados para abastecer a las hilanderías de la península Hispánica. Puede decirse que coloca al trabajo femenino en estrecha vinculación con el problema del ocio y un saneamiento de tipo educativo para el progreso local. Las mujeres abandonadas a la holgazanería, tanto o más que los hombres, debían ser entrenadas para el uso de sus habilidades en el hogar o fuera de él como servicio, de modo de contribuir a su sustento y alivianar la carga de sus padres. De este modo, serían madres de familias "útiles" y ocupadas en trabajos lucrativos (Belgrano 1796, p. 76).

Su propuesta preveía escuelas gratuitas para inspirar el "amor al trabajo", donde se enseñara a las niñas doctrina cristiana, lectura, escritura, costura y bordado -separadas de los varones para mayor utilidad-. También proponía como novedad la instalación de escuelas de hilazas de lana, alternativa que evidencia la influencia en Belgrano de las ideas a favor de las escuelas patrióticas españolas para remedio, una vez más, del ocio e indigencia de la juventud. Los pobres y los niños debían recibir lana y útiles de hilado también en sus casas, en caso de no poder salir. Además debía proveérseles trabajo en las escuelas para promover la venta de lanas hiladas en las fábricas peninsulares, extendiendo el hilado al algodón, o al menos su desmote y limpieza para facilitar su envío a ultramar (Belgrano 1796, p. 77).

La Junta de Gobierno del Consulado de comercio debía, a juicio de Belgrano, ser el instrumento de canalización de un proyecto que, de la asociación entre monarquía, consulado y educación en base al premio, resultase en la puesta en práctica de un plan "útil a nuestras provincias". El esfuerzo debía acompañar al rey, protector que buscaba asegurar la felicidad de sus vasallos "para que reinase la abundancia entre todas las clases del Estado" (Belgrano 1798, p. 100).

En cuanto al plan perfilado para fomentar el trabajo e impulso económico del Virreinato, pensaba en concreto en las posibilidades de explotación de los recursos naturales para generación de insumos para textiles, que además podía aportar para reducir los costos locales de transporte por agua. La dependencia mutua entre agricultura y comercio, noción derivada de los principios fundamentales de la economía política de la época que señalaba a ambos como pilares de la felicidad pública, significaba la necesidad de cooperación entre hacendados y comerciantes locales con sus conocimientos para la "utilidad pública". Si bien reconocía la importancia de la agricultura, señalaba el aporte necesario del comercio y la industria para frenar el encadenamiento entre miseria, desgracia y holgazanería (Belgrano 1798, p. 102). En este punto remarca las 
máximas de Quesnay sobre libre exportación de producción agrícola y libertad de comercio en general. Es sabido, además, que Belgrano realizó la primera traducción de sus escritos al español por la admiración que le profesaba (Navarro Floria, 1987). También esta memoria remite a sus lecturas de Genovesi, al resaltar la necesidad de recurrir al honor y al premio como frenos a la pereza del espíritu humano (Belgrano, 1798, p. 106). Ambas referencias son prueba de su asimilación de ideas francesas y, sobre todo, de las napolitanas, de gran auge en aquel momento en Europa. De hecho, José Carlos Chiaramonte señaló que los posteriores trabajos periodísticos de Belgrano harán más notoria su recurrencia a Antonio Genovesi (1989, p. 121). En lo que respecta a la utilidad pública, José Enrique Covarrubias señaló la frecuencia con que la corona española invocó el ideal de "vasallo útil" al momento de publicitar sus reformas del siglo XVIII; noción entendida como de tipo personal y social. Para los reformadores dieciochistas era considerada una condición sine qua non para la transformación de la vida pública en escenario de bienestar moral, tanto para el individuo como para la colectividad, y, por tanto, criterio básico orientador de la marcha de los asuntos públicos. La utilidad como virtud, complementada con los principios de preservación de la propia monarquía y de su pueblo (2005, pp. 436-445).

En sintonía con esa acepción de utilidad -y en función de pensar su rol de secretario y hombre útil a la patria $^{\mathrm{ii}}-$, Belgrano decidió presentar a la junta de gobierno del Consulado una reflexión concreta sobre las utilidades potenciales para la Península y para el Río de la Plata del cultivo del lino y del cáñamo. Incluía instrucciones de las particularidades de ejecución a la manera en que las Sociedades Económicas peninsulares presentaban sus informes con fines prácticos y pedagógicos (Belgrano 1797, p. 81). Con ello respondía a la vez al interés de la Corona de promover esos cultivos según lo establecido en la ley 20, título 18 del libro IV de Indias de 1545 , en cuyo texto Carlos $\mathrm{V}$ encargaba a virreyes y gobernadores la siembra y explotación en Indias con aplicación de la población indígena al hilado y tejido del lino. Esto significaba que como secretario acataba los lineamientos generales de la Monarquía para América (Belgrano, 1796, p. 82). En la segunda mitad del siglo XVIII las autoridades (entre ellos el ministro Campomanes) promovieron oficialmente la producción de plantas textiles para favorecer la manufactura rural, complemento ideal de la economía agraria doméstica. Al lino y al cáñamo tradicionales en la Península se agregaron nuevos, como el algodón, y las Sociedades Económicas y los párrocos rurales fueron el nexo principal para su difusión. En ese contexto, Galicia, desde varios siglos la región de mayor cultivo de lino y cáñamo, fue modelo para Campomanes de “industria popular o dispersa" (Piqueras Haba, 1991).

Para el Río de la Plata, Belgrano preveía el aporte de conocimientos sobre el tema, de manera que un nuevo recurso explotable y comercializable ("para nuestras necesidades y aumento de las comodidades") pudiese procesarse por "gentes del campo y los infelices de la ciudad") antes de pasar al proceso del telar. El insumo debía proveerse en condiciones de ser empleado en los telares de la Península y preveía la división de funciones por sexo: siembra, siega, remojo, cocimiento al sol, secado, a cargo de los hombres; puesta en fibras "a fuerza de maza" (incluía espalar, rastrillar e hilar), a cargo de las "esposas y otros infelices de la ciudad". En especial para las mujeres, "sexo desgraciado en este país, expuesto a la miseria y desnudez, a los horrores del hambre y estragos de las enfermedades derivadas", sería un freno a la prostitución, que impedía el matrimonio, doblegaba la salud y destinaba a las mujeres a mendigar. Su opinión sobre el trabajo femenino se fundaba en el conocimiento directo de la experiencia exitosa en Castilla, León y Galicia, de la realización de varias operaciones en torno al lino y cáñamo por mujeres. También remitía para otros ejemplos a testimonios contenidos en distintos pensadores de la economía; antecedentes todos que avalaban la atención de la situación "miserable del sexo privilegiado" y el logro de su aplicación al trabajo para reformar en última instancia las costumbres de la sociedad en su conjunto (Belgrano, 1797, pp. 80-84).

El proyecto alcanzaba en ese punto su conexión con la mejora del comercio, motor de prosperidad general en buena parte de las reflexiones económicas y políticas de la monarquía hispánica (Sánchez León, 2005). Para Belgrano, la puesta en marcha del proyecto aumentaría la riqueza del comercio por la propensión de los hombres a vivir con comodidad cuando "abundan sus medios". Esta cuestión remite también a los debates 
en torno al lujo positivo, otro de los tópicos de la época. Belgrano daba por sentado que los miembros del consulado poseían un giro de actividades y relaciones comerciales suficientes para tener conocimiento sobre los beneficios de un nuevo cultivo provechoso, como demostraba la experiencia peninsular (Belgrano, 1797, p. 84). Con base en los escritos de Campomanes, Belgrano pronosticaba los beneficios potenciales también para España, por tratarse de la provisión de un insumo escaso que frenaba las posibilidades de utilización en las escuelas de lencería e hilo creadas por la Monarquía, como era el caso de las de Galicia y las del Principado de Asturias. La apertura de importaciones libres de derechos por tales puertos otorgaba posibilidades de beneficios mutuos, además de la sustitución de las importaciones de lienzos confeccionados, que circulaban mayormente tanto en España como en América. Refería además a los diccionarios económicos y libros de circulación en aumento a partir del siglo XVIII. En especial citaba el caso del Diccionario Económico de Chomel, el Sócrates Rústico, los escritos de Marcandier en Chateaureux, Duhamel y otros escritos sobre el cultivo del cáñamo, entre otros, que podían ilustrar los lineamientos para la explotación (Belgrano, 1797, pp. 86-87).

Por otra parte, el estímulo al comercio previsto por Belgrano estaba en las fábricas de lonas, jarcias y cordelería, hasta aquel momento importados desde Europa y únicos renglones faltantes para la construcción local y para la habilitación de buques, puesto que había maderas en abundancia en la provincia, en el Paraguay y en Tucumán, además de excelentes terrenos para montes y minerales de brea en la jurisdicción de Salta, Mendoza y Sierra de la Ventana. El interés por la "ganancia" daría para Belgrano el tono y vigor a los brazos para extirpar la miseria por la inacción, "madre fecunda de los vicios numerosos en el virreinato" con posibilidades, además, de destinar el sobrante de producción a la "Isla de Francia", para la navegación hacia el oriente o al Brasil (como alternativa al piasábal para jarcias de inferior calidad). Por todo ello, los cambios debían realizarse con intervención conjunta de la Monarquía y de los "patriotas" del Virreinato (Belgrano 1797, p. 96).

La memoria, a semejanza de las elaboradas por las Sociedades Económicas de Amigos del País, incluía detalles ilustrativos del modo de siembra y cosecha, con inclusión de testimonios de granjeros locales que aportaban información sobre su experiencia en diferentes aspectos (Belgrano 1797, p. 92).

Además de los tópicos mencionados que impulsaron los escritos de Belgrano, otra cuestión también en boga era su referencia a la educación como nuevo pilar de desarrollo económico-político de la época. Se ha señalado a Jovellanos como uno de los precursores en la consideración de la educación como recurso dentro de las economías cuyas reflexiones han sido consideradas como pioneras de la teoría del capital humano, y representaban el cambio conceptual más sobresaliente del período dieciochista con sus alusiones a la felicidad como concepto paralelo al de educación (Street, 1988). En su concepción para el Río de la Plata, la educación tenía sentido práctico, impartida por escuelas específicas como las de náutica, dibujo, comercio, matemática, agricultura, y otras gratuitas para formación de las niñas (Belgrano 1796, pp. 55-80).

Las memorias ilustran que Belgrano no desaprovechó la oportunidad que le ofrecía su rol de secretario de la institución para difundir el resultado de su formación ilustrada. Ofreció además un plan concreto en condiciones de ser puesto en marcha para poner un espacio en los confines de la Monarquía a la par de lo que estaba implementándose en materia de recomendaciones de la economía política. Buscaba alinearse con las modificaciones operantes en la Península para que el Río de la Plata pudiese ser complementario y beneficiario a la vez de la política económica del momento.

Es útil remarcar, por último, que los argumentos esgrimidos por Belgrano -y los de la Junta de Gobierno del Consulado, como veremos- remiten en definitiva a la idea de una suerte de pacto entre la Corona y sus súbditos sobre el beneficio mutuo pasible de ser conseguido mediante la transformación de la Monarquía en una de tipo comercial aggiornada a la modernidad, al estilo de otros imperios como el británico o el francés, aunque sin olvidar la matriz católica. En tal sentido, resultan ilustrativas a nivel comparativo otras experiencias, como la impulsada por Victorián de Villava, fiscal de la audiencia de Charcas entre 1791 y 1802, 
quien constituye un ejemplo de promoción en la ilustración española de la idea de compatibilizar cultura católica con modernidad (Portillo Valdés, 2009).

\section{Entre discurso Ilustrado y realidad: las preocupaciones del Consulado de Buenos Aires}

¿Cuáles eran, no obstante las propuestas de Belgrano, los asuntos que ocupaban a los miembros del Consulado? Resulta interesante comparar el alcance de las ideas de Belgrano en las medidas y decisiones adoptadas en aquellos años por la institución, a la luz de las reformas concretas impuestas por la Corona. En líneas generales, pueden plantearse dos ejes de temas presentes en las actas de la Junta de Gobierno del Consulado: aquellos referidos a cuestiones puntuales derivadas de las reformas borbónicas "ilustradas" sobre comercio, fiscalidad, militarización, etc., y aquellos asociados a una intención pedagógica concreta que se pretendía difundir, resultado de la influencia de la economía política y de las intenciones de reformar al conjunto de la sociedad para el logro de una población en condiciones de acompañar a la Monarquía en el proceso de restauración de su antiguo esplendor.

La historiografía reciente ha aceptado la idea de que las reformas borbónicas fueron de gran influencia en el desarrollo de Buenos Aires y su entorno, al estimular la integración de la campaña demandando bienes de consumo y requiriendo bienes exportables como los cueros, con miras de proveer al exterior (Santilli, 2013). Si bien puede objetarse que los cambios en la estructura económica rioplatense se estaban esbozando desde tiempo antes, es conveniente reconocer, como hicieran varios estudios, que las reformas borbónicas tuvieron un efecto muy grande como para acentuar o acelerar esos cambios (Garavaglia, 1987; Halperin Donghi, 2005). Bajo la misma concepción, Daniel Santilli señaló que la legalización del monopolio comercial de Buenos Aires sobre el extremo sur de América, la creación del Virreinato del Río de la Plata, el establecimiento de su aparato burocrático y el aumento de la actividad económica condujeron al definitivo crecimiento económico de la ciudad, a la que se asignó en el mercado internacional el rol de abastecedora de subproductos ganaderos (2013, p. 248).

El Consulado comenzó a sesionar desde los primeros días de su erección. Los primeros integrantes fueron designados por la Corona previéndose para el futuro un mecanismo de elecciones y reemplazo periódico de los miembros. También se establecieron los representantes de las distintas diputaciones, designados entre los vecinos más destacados de la ciudad. Tal como estaba previsto, la institución se hizo cargo de cuestiones de justicia, donativos y demás cuestiones previstas en la cédula de erección, sin descuidar el contacto e interés por las jurisdicciones integrantes, hecho que se evidencia en el pedido y la recepción de informes por parte de sus diputados.

En relación al primer eje de temas vinculado a situaciones puntuales derivadas de la implementación de reformas por la Corona, existieron tópicos recurrentes tratados en sus reuniones. Un primer punto importante, como no podía ser menos, fueron los pasos a seguir en materia de derechos, impuestos y donativos, esenciales a nivel político y económico. El tratamiento de estos temas coincide con la intención de la Corona de lograr el fortalecimiento de la recaudación fiscal -de hecho alcanzado- a partir del blanqueamiento de operaciones comerciales antes no autorizadas que permitió la implementación del Reglamento de Libre Comercio de 1778 y el establecimiento de nuevos tributos, conceptos y jurisdicciones alcanzadas (Brading, 1990; Moutoukias, 1995). Martín Cuesta, más escéptico en su análisis respecto de las reformas, señaló que, efectivamente, el aumento de la recaudación fiscal sería uno de los pocos cambios que en definitiva aquellas dejaron, ya que, en su opinión, el crecimiento productivo de Buenos Aires se debió a motivos internos gestados desde antes y no por condiciones internacionales o el libre comercio (2009, p. 178).

En las actas se observa que el seguimiento y determinación de cuestiones relativas a la recaudación fiscal ocupó un lugar preponderante. En las reuniones no se descuidaban situaciones que involucraban deudas $\mathrm{u}$ otras cuestiones de inquietud sobre derechos de avería, alcabalas u otros impuestos especiales, como el 
aprobado por la Corona a favor del mantenimiento de la frontera de Córdoba del Tucumán -que generó el rechazo del Consulado con la solicitud de que solo se pagase en aquella jurisdicción y no en Buenos Aireso los derechos en Valparaíso sobre efectos comercializados de Buenos Aires a Lima. Lo mismo ocurre para el caso de tratativas también con el Consulado de Chile sobre la tasa obligatoria de entrada y salida de géneros en el puerto mencionado ${ }^{3}$. Los debates se dinamizaban en función de nuevos efectos introducidos o jurisdicciones involucradas, por los cuales el Consulado recibía los oficios de los diputados de la zona afectada. Tal es, por ejemplo, el caso en que se debatió en febrero de 1798 sobre el modo en que debía exigirse la alcabala de varios efectos ingresados por el puerto de Arica en Cochabamba según el método de recaudación de los derechos reales en La Paz y sus excepciones ${ }^{4}$.

En relación con las necesidades financieras, el tema de los donativos, mencionados por la historiografía como una de las funciones derivadas y cruciales del Consulado, aparece en entre los puntos tratados. En 1797 se consideraron donativos posibles de los comerciantes y la posibilidad de un préstamo a la Real Hacienda. Al año siguiente, ante urgencias financieras del cuerpo, se encomendó a dos consiliarios la obtención de "dinero a intereses" ". Viviana Grieco ha señalado la lealtad de los comerciantes bonaerenses implicada detrás de los donativos, aportes ampliamente recompensados de hecho con el derecho a establecer un consulado propio luego de una década de peticiones y gestión. Los donativos significaban beneficios políticos y financieros tanto para el rey como para los comerciantes (2014, pp. 3-13).

En segundo lugar, se hallaron los temas que buscaban el normal desenvolvimiento de la circulación entre las distintas jurisdicciones, como, por ejemplo, la navegación por el Paraguay. Una preocupación que aparece en las actas de los últimos años del siglo XVIII analizadas reflejaba las dificultades y abusos en la navegación por tal ruta, vía fundamental para el comercio fluvial desde el Río de la Plata hacia el norte. En varias reuniones la junta expresó la necesidad de superar tales inconvenientes ${ }^{6}$. Como parte de las iniciativas se solicitó, en diciembre de 1798, a Félix de Azara su colaboración por lo cual éste presentó un oficio sobre el arreglo de la navegación del Paraguay y se pasó la información al gobernador de Montevideo para proceder a la búsqueda de soluciones. También se analizaron las posibilidades de construcción de buques mayores en el Paraguay con libertad de derechos para traer los insumos necesarios traídos desde la Península, en un proyecto pensado para la felicidad de "estos dominios en utilidad del soberano y del Estado en general" ". La colaboración de Azara es prueba de la política de la Corona de recurrir a científicos y exploradores ilustrados para lograr un mejor reconocimiento de los dominios de la Monarquía y buscar mejorar actividades como la agricultura, promover el diseño de mapas de rutas y otras cuestiones complementarias para la comercialización. Como remarcó Jorge Gelman, Azara y Tomás de Rocamora, colaborador de Pablo de Olavide en Sierra Morena, fueron encomendados por la Corona para actividades de este tipo en América (2005, pp. 469-470).

En tercer lugar, y como temas que podrían calificarse de índole operativa o de preocupación diaria para promover el comercio, la Junta debía resolver sobre cómo mejorar las posibilidades de navegación y el estado de muelles e instalaciones. Lo mismo ocurría en conflictos suscitados en relación a buques comerciales puntuales, por cargamentos indebidos o transgresiones a la normativa vigente de los comerciantes a cargo. Tal como manifestara Gelman, el Consulado buscaba lograr un programa de controles para mejorar el uso de los derechos de propiedad y la libre disposición de los bienes, temas que involucraban indirectamente suprimir todo circuito irregular de comercio, incluido el transporte de bienes robados (2005, p. 468). La construcción del muelle para el puerto de Buenos Aires, por ejemplo, y la evaluación del estado del puerto de la Ensenada (con pedido al cónsul para gestionar un plano exacto del lugar) fueron cuestiones de especial atención, lo mismo que la construcción de fanales para auxilio de buques que entrasen en Montevideo ${ }^{8}$. Se incluyó el tratamiento de la necesidad de arreglar las barracas del Riachuelo, y acondicionar el desembarcadero para beneficio del comercio por la disminución de daños al momento del desembarco y embarco de cargas. Igual atención recibió el encargo de arreglos para el puerto de Barracas. Estas últimas cuestiones estaban asociadas 
también a un mejor ejercicio de los derechos individuales de propietarios y comerciantes para impulsar el comercio y la actividad general (AC, 1798, pp. 186-204).

Por aquellos años el Consulado resolvió contactar a Azara para la tarea de reconocimiento del Río Negro como vía de conexión entre Buenos Aires y el reino de Chile. Azara presentó un informe sobre la conveniencia de que el Virrey agilizara la exploración. Remitió un oficio con un plan "para buena parte del Virreinato", y el Consulado decidió solicitarle además los planos del continente ${ }^{9}$. Respecto del plan general, las actas no ofrecen información que permita conocer su contenido. De las actas de la institución solo puede saberse que Azara presentó un mapa general y cinco planos sobre la expedición al Río Negro, servicio por el cual se negó a recibir gratificación ${ }^{10}$.

El interés por el comercio de esclavos estuvo presente desde el comienzo de la actividad del Consulado. Uno de los objetivos era su vigilancia para evitar perjuicios a la Real Hacienda y al comercio local ${ }^{11}$. En noviembre de 1797 se tomó conocimiento de la "Real gracia", a favor de un comercio que introdujese negros provenientes de la costa africana, sumado a la posibilidad de extraer cueros o frutos sin pago de derechos reales ni municipales, incluidos los de guerra. Ante tal situación, el Consulado solicitaba su limitación o bien su abolición acorde al bien público ${ }^{12}$. Por otra parte, analizaban solicitudes de autorización puntuales para la introducción de cargamentos de esclavos ${ }^{13}$. No obstante los reparos que pudiesen existir, la intención de promover ese tipo de comercialización era explícita, como se expresaba a comienzos de 1798, sobre la necesidad de habilitar el puerto para facilitar el tráfico entrante de esclavos. La Junta aclaraba que esto no significaba proteger el contrabando sino procurar evitarlo. Se buscaba recibir a todas aquellas embarcaciones que no tuviesen real determinación en contra. El contrabando no se veía como motivo para impedir los arribos, pues se contaba con funcionarios como ministros y subalternos para su control. La institución decía desconocer que se estuviese practicando el contrabando (a propósito de denuncias recibidas contra comerciantes reconocidos como Pedro Duval de Barragán, Francisco Beláustegui o José de María); pedía conservar la habilitación del puerto concedida por los soberanos, y que fuese "libre y franco" el arribo de las embarcaciones para todo comercio libre permitido ${ }^{14}$. Existen dos cuestiones a considerar en este punto: por un lado, el problema del contrabando, y, por el otro, la figura de Pedro Duval, dado que remite a un tema controvertido durante el siglo XVIII como fue la discusión en torno al comercio esclavista y la consideración o no de los cueros como "frutos del país".

En relación al contrabando, Fernando Jumar e Isabel Paredes expusieron -acerca de las distintas maneras en que éste se presentó- el frágil equilibrio de intereses que regía la vida del complejo portuario rioplatense y las estrategias de sus habitantes para maximizar oportunidades económicas. Con esto ampliaron los análisis centrados en los grandes comerciantes (Jumar y Paredes, 2008; Jumar, 2016). Estos trabajos complementaron a anteriores, como los de Zacarías Moutoukias, quien había revelado, a partir de distintos procesos por contrabando en el Río de la Plata en la segunda mitad del siglo XVIII, las diversas tramas ocultas de relación, de parentela y de poder existentes detrás de lo que a simple vista parecían únicamente casos de comercio ilegal. El contrabando le ofreció una vía de ingreso para desentrañar otras cuestiones presentes en la sociedad comercial rioplatense, donde las redes de relación reafirmaban un tipo particular de consenso colonial. Para los representantes de la corona, esos tejidos de relación eran las estructuras informales que permitían reclutar a la élite local para contribuir a los objetivos imperiales. Para las familias notables, los cargos políticos y militares, como las relaciones con representantes de la Corona, eran fuentes de influencia política, prestigio, autoridad y poder, bases de la movilidad social y apropiación de la renta económica. A partir, entonces, de disputas ordinarias sobre el problema del contrabando, quedaron en evidencia las prácticas y estrategias que unían a determinados grupos de personas y familias interconectadas a lo largo de generaciones, en las que la organización de empresas guardaba estrecha relación con las estructuras de poder político (Moutoukias, 1988, 1992). La mencionada figura de Pedro Duval es ilustrativa de ello y de la tensión económica y política detrás de la actividad comercial, analizada recientemente por Mariano Schelz (2016, pp. 133-154). 
En relación a la disputa sobre el tráfico de esclavos y a la consideración de los "frutos del país", los años 1780 a 1810 representan un período de grandes confrontaciones. Susan Socolow caracterizó a la década de 1780 como aquella en la que un grupo de comerciantes involucrados en la trata de esclavos (Tomás Romero, Pedro Duval, Nicolás Acha y Manuel de Aguirre) comenzaron a ser atacados por su creciente prosperidad, que amenazaba la posición social y económica del grupo más tradicional (encabezados por José Martínez de Hoz, Jaime Alsina y Verjes, Diego Agüero, Joaquín Pintos, Esteban Villanueva, Joaquín de Arana y Luis Gardeazabal). Este segundo grupo se opuso a Romero, el esclavista más próspero y audaz, ante la perspectiva que tenía éste de participar en 1784 en un comercio triangular con España y África, exportando cueros a cambio de esclavos (1991, p. 144). Como planteó Mariano Schlez, el tema remitía a una situación histórica. España no había participado en la conquista territorial de África y no podía garantizar el abastecimiento constante de esclavos, por lo cual otorgaba permisos con el objetivo de fomentar la trata en todo el imperio. En el contexto borbónico de fomento del comercio y el progreso, la Corona extendió nuevas autorizaciones en 1792 para vender en el Río de la Plata. Ello permitía obtener un margen considerable de ganancia con la exportación de frutos americanos a puertos neutrales. Los comerciantes españoles vinculados a Cádiz, fracción predominante, se negaban a aceptar que los esclavistas exportaran productos a puertos extranjeros fuera de la vía gaditana, e insistieron en sucesivas presentaciones para detener el tráfico, primero desde la Junta de Comercio y después, a partir de 1794, en el flamante consulado. El tema se agravó cuando nuevos comerciantes comenzaron a sumarse a la trata, con lo que los comerciantes decidieron elevar la protesta no atacando al comercio de esclavos sino al intercambio de ellos por cueros, que en su opinión no debían considerarse frutos del país. No obstante, la Corona ratificó a los cueros como frutos exportables en 1796. La ola de enfrentamientos se agudizó mientras los esclavistas ganaban adeptos, en un período en el que el mencionado Pedro Duval tuvo un rol destacado en las deliberaciones para que no decayeran los permisos frente a las hostilidades manifiestas de quienes querían impedir exportar cueros a puertos extranjeros por fuera de la vía gaditana, que ponía en juego los privilegios monopolistas rioplatenses (2016, pp. 144-147).

Respecto de la representación en el organismo de hacendados y comerciantes, a pesar de la importancia del tema, la preocupación por que en el Consulado estén representados en igual número ambos sectores aparece en una única oportunidad asentada en actas en $1797^{15}$. Entre otros temas puntuales incluidos en las actas consta la preocupación por el ingreso de géneros extranjeros prohibidos por el puerto de Montevideo, consideraciones sobre los mecanismos de elección de situadistas, multas por falta de solicitud de habilitación de almacenes, aprobación de festividades patronales, tareas de contralor con inspecciones a tiendas, o pedidos de exenciones a milicias por parte de comerciantes ${ }^{16}$.

Resta considerar el segundo eje de temas mencionado al comienzo de este apartado sobre cuestiones puestas a debate, que podrían ser calificadas como de "interés Ilustrado", y que coincidían en parte con las preocupaciones de Belgrano. Sin embargo, no puede saberse, a partir del contenido de las actas, si la consideración de la Junta sobre ellas respondió a la influencia de su secretario o se originó en un interés ilustrado propio del resto de los consiliarios.

En primer lugar, destaca el interés por un comercio más activo con las colonias extranjeras en el marco de la necesidad de fomento de la agricultura, comercio y navegación en América, en vista del atraso que sufrían desde la conquista por la falta de libertad en tres ramos valorados como los "más interesantes al Estado", todo ello sumado a la idea de que la agricultura debía suministrar alimentos baratos y aportar para superar la pobreza de labradores. Ello debía cumplirse con la incorporación de conocimientos, aprovechando los estímulos y franquicias que la Corona española incitaba para comenzar a experimentar y arriesgar hacia la "obra de nuestra felicidad"17. La influencia ilustrada se transluce en referencias a la traducción del marqués de Condorcet de la obra de Adam Smith sobre la riqueza de las naciones, que aludían a la cuidada elaboración de la reglamentación de comercio de las Américas trabajada por el ministro de hacienda de la Corona, en bien común del Estado. La Junta remitía a las reglas de la economía política en cuanto a balanza comercial para explicar los beneficios económicos del plan. Uno de los consiliarios a favor del libre comercio, Tomás 
Hernández, explicaba las ventajas de la economía política como ciencia cultivada en Europa e ignorada en América; ciencia a la que debían su grandeza otros reinos y sin la cual ninguna monarquía podía gobernarse con acierto; ciencia de principios y máximas sublimes que exigían estudio profundo para su aplicación oportuna a casos, lugares y tiempos. Por tanto, planteaba la necesidad de que los fundamentos a exponer al soberano fueran revisados a la luz de tales principios y con referencia a las circunstancias del país ${ }^{18}$.

Como consecuencia de buscar un comercio más activo, no podían dejar de tratarse cuestiones locales que entorpecían tal objetivo. Así, por ejemplo, preocupaban los inconvenientes informados por los diputados al momento de comerciar en otras jurisdicciones, como la denuncia por medio de dos oficios -enviados por el diputado en Mendoza - sobre las desventajas de nuevas disposiciones del cabildo sobre la descarga de carretas y la circulación hacia los trapiches. Estas circunstancias daban lugar a la consideración de las dificultades y el pedido de medidas correctivas a las autoridades ${ }^{19}$. La Junta celebraba que la idea de progreso guiase a Carlos IV en sus decisiones para el bien general de la Monarquía y la felicidad de sus vasallos; principios rectores presentes en el discurso ilustrado borbónico. Por ello, se acataba que, a fin de evitar los "graves e irreparables perjuicios" que las condiciones del momento generaban en el comercio de sus dominios, el monarca hubiese acertadamente (a juicio de la Junta) permitido las expediciones de efectos "no prohibidos en buques nacionales o extranjeros desde puertos de las potencias neutrales o desde los de España" ${ }^{20}$. No se dudaba que cumplir la voluntad real de apertura del comercio redundaría en un gran beneficio a nivel local. La continuidad de la guerra interrumpía el comercio, las colonias padecían, según los consiliarios, perjuicios graves con la baja de utilidades comerciales y la falta de géneros europeos, algunos de mucha necesidad. Estas causas dieron lugar al permiso para envíos extraordinarios ${ }^{21}$. Los daños no podrían repararse hasta que no se autorizara la libre exportación de los frutos del país y la introducción de géneros faltantes. Si bien se infería de una real orden del 20 de mayo de 1798 que los motivos de la autorización eran la continuidad de la guerra, la interrupción del comercio y la baja en la recaudación del erario por la falta de caudales desde sus dominios, el beneficio se extendería a la monarquía en su conjunto. En las exposiciones se buscaban ejemplos de otras experiencias, como el de la Habana, donde, por causa de haberse permitido el flujo en buques neutrales, se había logrado enriquecer a los pueblos con la venta de sus cosechas abundantes a precios altos. Se importaron efectos a precios convenientes y aportaron sumas importantes a las rentas reales para cubrir las urgencias de la Corona. No obstante, proponían los efectos que debían prohibirse para evitar el perjuicio de la competencia, como era el caso del azúcar del Brasil, que podía dañar el comercio de Lima, Arequipa, Cuzco, San Juan y Mendoza. Además existían otras consideraciones que se preveía exponer al virrey como informe solicitado a la Junta para aceitar el funcionamiento del sistema en beneficio local ${ }^{22}$.

La preocupación de la Junta de Gobierno por el estado de decadencia general, tema clave en la Europa de la época, fue tratada puntualmente en reunión de noviembre de 1798. El día 3 de noviembre se consideró proporcionar los medios para el restablecimiento del comercio, agricultura e industria de las provincias: brindar reglas para conservar esos tres grandes resortes de la felicidad general, prevenir la decadencia, dar subsistencia, ocupación, ganancia y prosperidad al continente a partir del aumento de los ingresos del erario real y las ventajas de la Corona. Tales importantes objetivos eran propuestos por el cabildo bonaerense al administrador de la Real aduana de Buenos Aires, al virrey y a la Junta de Gobierno del Consulado.

De manera similar a los escritos de pensadores europeos que recurrían a la historia y a otros escritos para refrendar sus ideas, los consiliarios remitían a las ideas posteriores al pensador espartano Licurgo, a las de Platón en su república imaginaria, y a aquellas que transformaron la idea de conquista en una quimera, para dar paso a la noción subyacente en todas las potencias del mundo de que el comercio era la base de la riqueza, "todo el mundo está persuadido que los tesoros son el alma de la sociedad y que ninguna nación puede ser feliz sin el comercio que los produce y le da toda la energía y el vigor". Era de fácil comprobación que "únicamente de la opulencia” dependía la actividad de una nación, sus costumbres, la bondad de sus leyes, la efectividad 
de su política, las disposiciones interiores para mantener el buen orden, los programas de artes y ciencias, el éxito en las negociaciones y, sobre todo, su poder por mar y tierra ${ }^{23}$.

$\mathrm{Al}$ igual que círculos ilustrados de la Península, la junta de gobierno del Consulado demostraba interés por los conocimientos prácticos en materia de economía, que circulaban en ediciones en boga en distintos formatos (Astigarraga y Zabalza Arbizu, 2007). En sus actas consta un caso de solicitud al apoderado en Madrid para que, junto a diecisiete ejemplares de las ordenanzas de Bilbao, de Indias y Castilla, procurase una copia del diccionario de agricultura de Rozzier ${ }^{24}$.

La importancia del Consulado como organismo para la difusión de ideas novedosas y el progreso era percibida por sus integrantes como esencial, al punto que la mera lectura de sus memorias al público la consideraban un acto ilustrado de "general instrucción" y estímulo. Con presencia de autoridades, comerciantes y hacendados instruidos, junto a "literatos" que pudiesen transmitir conocimientos económicos, la difusión de las "luces podía expandirse a todas las clases del Estado". La memoria de 1798 indica que "estos congresos son el mejor medio para que todos se instruyan y por eso en todas las naciones cultas se apresuraron a establecer sociedades y academias con la publicación de sus memorias" 25 . Ese era el objetivo que el cuerpo consular ambicionaba alcanzar a falta de otras instituciones de difusión como las que habían prosperado primero en Inglaterra y luego en Francia, Italia, Suiza, Alemania, Dinamarca, Suecia, Rusia, y otras con cátedras de Economía Política, en las que la erudición escolástica se combinaba con "conocimientos útiles para la vida". Este ejemplo fue seguido por la Península con gran número de sociedades económicas y con el estudio de la economía política ${ }^{26}$.

Con relación a las propuestas de Belgrano en sus memorias, las actas dan cuenta de la puesta en práctica de alguna de ellas. En primer lugar, la noción de premio como estímulo para las mujeres se planteó por primera vez en setiembre de 1797 con la idea de premiar a las niñas huérfanas a través de la junta de caridad ${ }^{27}$. Las distinciones serían para las huérfanas del Colegio de San Miguel que más sobresalieran en la perfección de hilazas de algodón. El Consulado se comprometía a entregar dos premios de 30 y 40 pesos fuertes: el primero a la niña de dieciséis años o mayor que mereciese el segundo lugar en el hilado de una libra de algodón "hilado igual, delgado y pastoso", y el segundo para la menor de dicha edad que, con certificación de la maestra encargada, presentase también una libra de algodón de iguales características ${ }^{28}$. Al año siguiente, la institución decidió destinar 500 pesos a premios para fomentar la agricultura, las artes y el comercio ${ }^{29}$. Según la facultad que el rey concediera por real orden de marzo de 1797 enviada al secretario, la Junta de Gobierno decidió premiar con 50 pesos, en primer lugar, a quien con certificaciones de los párrocos y diputados del Consulado, o en su defecto de los jueces ordinarios, hiciese constar la introducción de un nuevo cultivo provechoso, con arreglo al clima y circunstancias de la provincia en que lo ejecutase, e hiciese ver en una memoria las ventajas que traería al comercio particular del país y "general de la Nación”. En segundo lugar, se premiaría con 50 pesos a quien probara el establecimiento de una huerta y monte de árboles útiles en el puerto de la Ensenada de Barragán. Sería preferido quien demostrase haber plantado mayor número de árboles y haber cultivado más hortalizas. El tercer premio, de otros 50 pesos, sería para quien informase el medio a adoptar para efectuar grandes plantaciones con árboles útiles en la jurisdicción de Buenos Aires "sin necesidad de poner cercas". El cuarto y quinto premio, de igual monto que los anteriores, beneficiaría a quien enseñara el modo de tener aguadas permanentes en las campañas y a quien propusiese un método fácil y económico de exterminar los perros cimarrones de los campos. El sexto premio, por 500 pesos, a quien presentase un método para preservar cueros de la polilla. Además, se otorgaría una pensión vitalicia, de otros 500 pesos, a quien lo pusiese en práctica. Por último, 100 pesos se destinaban a quien informara el estado de la población de cualquiera de las provincias del Virreinato (con preferencia Buenos Aires), con distinción de clases y ocupaciones (por cultivo, por tareas, productos de esos ramos, consumos, etc.). ${ }^{30}$

Las propuestas de Belgrano sobre la explotación del lino y cáñamo tampoco fueron desatendidas por el Consulado. El 18 de noviembre de 1798 Martín José de Altolaguirre, vecino de Buenos Aires, ofreció a la 
Junta las porciones de tales cultivos que fuesen necesarias de las sembradas en sus haciendas para disponer y efectuar las pruebas que se decidiesen. De igual modo, ponía a disposición sus instrumentos para el primer beneficio -como la noria y estanques que tenía en su quinta junto a los recoletos de la ciudad- hasta poner a la producción en estado de hilarla. Los vocales de la Junta, que tenían presentes las ventajas que esa rama de la agricultura podía traer a la provincia y metrópoli, acordaron por unanimidad comisionar a los conciliares Pedro Duval y Agustín García para que se ejecutaran las pruebas más apropiadas para lograr la instrucción necesaria de la utilidad que podía conseguirse con ellas. Además, debían averiguar los costos necesarios hasta poner la explotación en condiciones. Se agradecía por otra parte a Altoaguirre por su "liberalidad y patriotismo" ${ }^{\prime 3}$. Cuatro meses después, los consiliarios comisionados para el ensayo presentaron informe de los recursos necesarios que se insumirían hasta la finalización de las pruebas. El cáñamo debía trabajarse para satisfacer los encargos de la Corona, que al momento solicitaba una cantidad de producción que debía venderse en valor aproximado de 500 pesos $^{32}$.

Dentro de las que podríamos mencionar como otras experiencias "ilustradas", se refirió en otra sesión al encargo a dos vecinos para que experimentasen con una máquina de limpiar trigo de reciente aparición e instruyesen luego sobre sus resultados ${ }^{33}$.

Por último, la creación de escuelas prevista por Belgrano se materializó por intermedio del Consulado, en el último año del siglo XVIII, en el establecimiento de la escuela de dibujo y poco después la de náutica. En agosto de 1798 comenzó a evaluarse el presupuesto necesario para su institución, luego de algunas reuniones y de un pedido de dictamen a Félix de Azara sobre la factibilidad de la escuela de náutica. Ambas escuelas comenzaron a funcionar al año siguiente en instalaciones del Consulado, en su sala de depósito, con inscripción en secretaría de los niños interesados en concurrir, y con consideración anticipada de los futuros premios a otorgar ${ }^{34}$. Como institución integradora de las distintas jurisdicciones virreinales a través de las diputaciones fijadas para las principales ciudades, supo atender inquietudes educativas presentadas por sus diputados, como fue el caso de la propuesta de subsanar la falta de una escuela de primeras letras en Santa $\mathrm{Fe}$, por lo que se encomendó al diputado interviniente la presentación de un informe de factibilidad para su instalación y mantenimiento con los arbitrios correspondientes a la comercialización de yerba del Paraguay ${ }^{35}$.

A los temas analizados en este apartado se sumaron otros que solo aparecen tratados de modo rápido, sin mayores debates entre los consiliarios, como demoras en el transporte de correo, presupuestos de reparaciones edilicias, diagramación del ingreso del transporte terrestre a la ciudad, inspecciones sanitarias para los envíos de esclavos, o construcción de fuertes para defensa en las distintas jurisdicciones en peligro de ataques indígenas. Todas estas situaciones, si bien hacían a la seguridad, circulación o sanidad, parecen haber tenido el carácter de habituales y al parecer no generaban mayor intranquilidad para los vecinos.

\section{ConClusión}

La historiografía ha dado cuenta de las distintas facetas que el Consulado de Buenos Aires desempeñó, al igual que sus pares en territorio americano. La figura de Belgrano como su secretario y su formación en el exterior hizo que éste lo pensara como canalizador de un proyecto ilustrado sobre todo a través de su junta de gobierno, para la cual pretendía en parte un rol pedagógico y práctico a la manera de las Sociedades Económicas de Amigos del País peninsulares.

No puede negarse la representatividad del caso de Belgrano en la transición cultural, política y económica operada entre el Virreinato y la Revolución, además del impulso reformador con que emprendió su gestión, que recuperó temas fundamentales de la agenda política y económica europea para trasladarlos, en una suerte de hibridación y readaptación, al contexto local, y ofrecer así una propuesta beneficiosa que se acoplara de manera armónica al plan de progreso de la monarquía hispánica. En tal sentido, su identificación de recursos naturales concretos, vinculados a los textiles -actividad promocionada en la Península-, su explotación para 
provisión de insumos a la Corona, el beneficio complementario para el comercio local con disminución de costos de transporte y otros beneficios resultaba una propuesta que, si bien significaba en suma estrechar y perfeccionar la situación de dependencia con la Monarquía, respondía a un plan "ilustrado" completo y digno de ser considerado al nivel de los postulados por intelectuales europeos del momento. Los puntos señalados por Belgrano respondían a algunos de los más candentes en las discusiones europeas: la identificación del "otro" ocioso, símbolo de ralentización de las economías, la erección de las Sociedades Económicas en entidades emblemáticas del progreso en su accionar pedagógico-práctico, los frenos al comercio, agricultura e industria, y, sobre todos ellos, lo que podríamos denominar la "cuestión femenina" en torno al ocio. Ese "otro" es el caso identificado con la población femenina, respecto de la cual Belgrano expone la necesidad de conectarla al mundo del trabajo. La escuela de hilazas es un ejemplo en ese sentido. La escuela cumplía el triple rol de impulsar un sector de la economía, conectarlo con la exportación de insumos y, por sobre todo, incorporar a las mujeres al mundo del trabajo. Belgrano no solo recuperaba el tema de la vagancia, sino el de la prostitución, también unida al universo femenino, en su discurso y en el discurso europeo. Y, entre otros puntos que se han desarrollado con mayor precisión en páginas anteriores expone el de la educación como inversión a futuro para formar en lo práctico, pero a la vez para inculcar el trabajo voluntario en el paso hacia una economía moderna, en la cual el esfuerzo fuese visto como una opción de progreso, lo cual convierte a la educación en capital, a la manera de Jovellanos.

El Consulado de Comercio de Buenos Aires, en especial su junta de gobierno, que tanto interés despertaba en Belgrano, supo estar a la altura, en la medida de sus posibilidades, de ese rol "Ilustrado" que su secretario pretendía. De las actas recorridas se observa que debían ser resueltas necesidades puntuales y urgentes, propias de una economía tardocolonial, en muchos aspectos en transición, con necesidades de infraestructura, defensa frente al indígena, tierras aún en exploración, con demarcaciones y rutas mayormente diseñadas a fuerza de ensayo y error. La institución también debía cumplir con su rol de recaudación, préstamos y donativos, tan necesarios para la Corona como para el logro de beneficios para los miembros de la elite comercial local, como ha demostrado la historiografía. No obstante, no podemos determinar si por influencia de Belgrano o por interés propio del resto de los consiliarios, los temas ilustrados circularon por la institución y el proyecto de su secretario fue, aunque de manera tibia, concretado o movilizado en ciertos aspectos.

Los discursos respecto de los beneficios del comercio, la preocupación por la decadencia general, las referencias a los escritos recientes de Adam Smith, la necesidad de aplicar las reglas de la moderna economía política (incluso de responder a las cédulas de la Corona con terminología precisa y correcta), la adquisición de diccionarios económicos europeos y la apertura al público en general para dar a conocer al menos las memorias anuales de la institución dan cuenta de su interés por formar parte de la agenda europea de reflexiones. Respecto de las propuestas de Belgrano, si bien las medidas puestas en práctica son ínfimas en comparación con lo esperado por aquél, se efectuaron algunas experiencias en torno al lino y cáñamo, y se otorgaron algunos premios a niñas ejemplares (si bien no resulta comparable con la cantidad de distinciones entregadas por las Sociedades Económicas españolas, tal como consta en numerosos volúmenes impresos con el detalle de los premiados). Existe una única mención a la experimentación con maquinaria agrícola (referencia inexistente si se la compara con el sinnúmero de demostraciones de todo tipo que publicaba por aquél entonces, por ejemplo, la Sociedad Matritense de Amigos del País) y de las escuelas pensadas por Belgrano solo la de dibujo y náutica fueron instaladas.

En suma, sea porque las medidas de contenido ilustrado interesaban a una parte considerable de los consiliarios, o bien porque respondieran a inquietudes y representaciones propuestas por vecinos, o bien por insistencia de Belgrano, el hecho es que, aunque de manera tibia, los temas ilustrados estuvieron presentes en las reuniones de la Junta de Gobierno. Puede decirse que a fines del siglo XVIII, antes de que la prensa se constituyera en una alternativa de nuevo corte para la expresión de opiniones y propuestas ilustradas, el Consulado de Comercio fue un espacio de aporte para las nuevas preocupaciones de la Economía Política readaptadas a la realidad local, en una jurisdicción que no desconocía su carácter virreinal y dependiente de la 
Corona, aunque planteaba necesidades y opciones propias, más allá de los intereses particulares de los sectores que componían el cuerpo consular.

\section{Fuentes}

AGNC. Archivo General de la Nación (1936). Consulado de Buenos Aires, Antecedentes, Actas y Documentos, I, años 1785-1795. Buenos Aires: Kraft Ltda.

AJGCBA. Archivo General de la República Argentina (1895). Libros Actas del Consulado. Tomos III y IV. A. Carranza (dir.). Buenos Aires: Imprenta Kraft.

Belgrano, M. (1796). Medios generales de fomentar la agricultura, animar la industria, proteger el comercio en un país agricultor. Museo Mitre (1913). Documentos del Archivo de Belgrano. Tomo 1, Buenos Aires: Imprenta Coni.

Belgrano, M. (1797). Memoria escrita por el licenciado Manuel Belgrano, abogado de los reales consejos y secretario por su majestad del real consulado de Buenos Aires en 1797. Museo Mitre (1913). Documentos del Archivo de Belgrano. Tomo 1, Buenos Aires: Imprenta Coni.

Belgrano, M. (1798). Memoria que leyó el licenciado don Manuel Belgrano, abogado de los reales consejos y secretario por su majestad del real consulado de esta capital en la sesión que celebró su junta de gobierno á 14 de junio de 1798. Museo Mitre (1913). Documentos del Archivo de Belgrano. Tomo 1, Buenos Aires: Imprenta Coni.

\section{Bibliografía}

Astigarraga, J., y Usoz Otal, J. (2008). Del A. Genovesi napolitano de Carlo di Borbone al A. Genovesi español de Carlos III: la traducción española de las Lezioni di commercio de V. de Villava. Cuadernos de Historia del Derecho, 5, 293-326.

Astigarraga, J., y Zabalza Arbizu, J. (2007). Los diccionarios de Comercio y Economía en el siglo XVIII español. Revista de historia industrial, 35, 13-46.

Betancourt Castillo, F. (2012). Los comerciantes españoles y el proceso de independencia en Chile. Estrategias y desventajas en una época de cambios. Tiempo histórico, 4, 121-138.

Bolufer Peruga, M. (2011). Femmes et hommes dans la société idéale: les Sociétés Économiques des amis du pays dans l'Espagne des lumières. Dix-huitiéme siècle, 43, 434.

Botella Ordinas, E. (2015). Olvidar a John Locke: invasión de América, colonización de España e invención de Inglaterra. Argumentos de derecho de gentes en las disputas hispano-británicas por el Yucatán, la Carolina y Darién. Magallánica, Revista de Historia Moderna, 3, 8-30.

Bottarini, R. (2010). La escuela y el premio. El programa ilustrado de Manuel Belgrano: medios generales de fomentar la agricultura, animar la industria, proteger el comercio en un país agricultor. Historia y Educación, 29, 285-305.

Brading, D. (1990). La España de los borbones y su imperio americano. En L. Bethel (ed.), Historia de América Latina (pp. 85-126). Madrid: Crítica.

Calvo, N. (2008). Voces en pugna. Prensa política y religión en los orígenes de la República Argentina. Hispania Sacra, $122,575-596$.

Covarrubias, J. (2005). En busca del hombre útil: un estudio comparativo del utilitarismo neomercantilista en México y Europa (1748-1833). México: Universidad Autónoma de México.

Crespi, L., y Salles, E. (2002). Bases y fuentes documentales para el estudio del tribunal del consulado en el Río de la Plata. América Latina en la Historia Económica, 9(17-18), 53-62. https://dialnet.unirioja.es/ejemplar/377267

Cruz Barney, Ó. (2002). Operaciones mercantiles y consulados de comercio en el mundo Hispano-Indiano: notas sobre su estudio. América Latina en la Historia Económica, 9(17-18), 157-168. https://dialnet.unirioja.es/ejem plar/377267

Cuesta, M. (2009). Precios, población, impuestos y producción. La economía de Buenos Aires en el siglo XVIII. Buenos Aires:Temas Grupo editorial. 
Cuño Bonito, J. (2009). El consulado de comercio. Cartagena de Indias y su papel económico y político en el conflicto de independencia (1795-1821). Studia Histórica, 27, 311-348.

Chiaramonte, J. (1989). La Ilustración en el Rio de la Plata. Cultura eclesiástica y cultura laica durante el Virreinato. Buenos Aires: Sudamericana.

Dánvila y Villarrasa, B. (1779). Lecciones de Economía Civil o de El Comercio. Madrid: Joaquín Ibarra Impresor de Cámara de S.M.

De Arriquibar, N. (1779). Recreación politica. Reflexiones sobre el amigo de los Hombres en su tratado de población, considerado con respecto a nuestros intereses. Vitoria: Tomás de Robles y Navarro, Impresor de la Real Sociedad Bascongada.

De Jovellanos, M. (2012). Introducción a un discurso sobre la economía civil y la instrucción pública, 1797. Revista Asturiana de economia, 45, 181-194.

Del Carmen Bistué, N., y Acevedo, A. (2015). De traficantes y negociantes y sus conflictos. La administración de justicia mercantil en la Mendoza virreinal (1776-1810). Revista Cruz del Sur, 5(14), 388.

Del Valle Pavón, G. (2015). Contraprestaciones por los servicios financieros del Consulado de México y sus miembros: los fondos extraordinarios para la guerra contra Gran Bretaña, 1779-1783. Revista complutense de historia de América, 41, 149-171. https://dialnet.unirioja.es/servlet/articulo?codigo $=5327734$

Di Meglio, G. (2008). Patria. En Goldman, N. (ed.) (2008). Lenguaje y revolución. Conceptos políticos clave en el Río de la Plata, 1780-1850. Buenos Aires: Prometeo.

Fernández Albaladejo, P. (2009). La crisis de la Monarquía, Madrid: Marcial Pons Crítica.

Fernández Albaladejo, P. (2015). Un cuerpo no tan muerto. Revisitando el escenario Ibérico, 1680-1740, Magallánica, Revista de Historia Moderna, 3, 1-7.

Fradkin, R. (2014). Antigüedad de asentamiento, orientaciones productivas y capital comercial en la conformación de una estructura regional: Buenos Aires XVIII y XIX. Revista de Historia (Universidad Nacional del Comahue), 5, 223-244.

Gallo, K. (2001). A la altura de las luces del siglo: el surgimiento de un clima intelectual en la Buenos Aires posrevolucionaria. En C. Altamirano y J. Myers (dir.) (2008), Historia de los intelectuales en América Latina (pp. 184-204). Tomo 1. La ciudad letrada de la conquista al modernismo. Buenos Aires: Katz Editores.

Gallo, K. (2002). Jeremy Bentham y la "Feliz Experiencia". Presencia del utilitarismo en Buenos Aires 1821-1824". Prismas. Revista de historia intelectual, 6, 79-96.

Garavaglia, J. (1987). Crecimiento económico y diferenciaciones regionales: el Río de la Plata a fines del siglo XVIII. En Economía, Sociedad y Regiones (pp. 13-64). Buenos Aires: Ediciones de la Flor.

Gelman, J. (1996). De mercachifle a gran comerciante. Los caminos del ascenso en el Río de la Plata colonial. España: Universidad Internacional de Andalucía. Sede Iberoamericana de La Rábida.

Grieco, V. (2014). The politics of giving in the Viceroyalty of Rio de la Plata: donors, lenders, subjects and citizens. Albuquerque:University of New México Press.

Halperin Donghi, T. (2005). Guerra y finanzas en los orígenes del Estado argentino (1791-1850). Buenos Aires: Prometeo.

Harispe, S. (2012). El descubrimiento del pueblo: Los discursos de la elite porteña frente a los sectores subalternos entre fines del siglo XVIII y los inicios del siglo XIX (Tesis de grado), Memoria Académica, Universidad Nacional de La Plata.

Hernández García, E. (2013). Las familias piuranas y su capacidad de comercialización en la segunda mitad del siglo XVIII. Mercurio Peruano, 526, 123-141.

Hora, R (2014). La elite económica argentina, 1810-1914. Revista de sociología e política, 22(52), 27-46.

Jumar, F. (2007). Comercio, comerciantes y revolución en el Río de la Plata: siglo XVIII-principios siglo XIX. En M. de Vivó, G. Martinière y R. Almeida (eds), Historias compartidas: Economía, sociedad y poder, siglos XVI-XX (p. 9). Lima: Pontificia Universidad Católica del Perú.

Jumar, F. (2016). El comercio ultramarino por el complejo portuario rioplatense y la economía regional, 1714-1778. Magallánica: revista de historia moderna, 5, 166-259. 
Jumar, R., y Paredes, I. (2008). El comercio intrarregional en el complejo portuario rioplatense: el contrabando visto a través de los comisos, 1693-1777. América Latina en la Historia Económica, 29, 33-99.

Jumar, F., y Kraselsky, J. (2007). Las esferas del poder. Hacendados y comerciantes de Buenos Aires ante los cambios de la segunda mitad del siglo XVIII. Anuario del Instituto de Historia Argentina, 7, 31-58.

Kraselsky, J. (2005). Los actores locales y su representación corporativa. Las Juntas de Comercio y su dinámica de funcionamiento. Anuario del Instituto de Historia Argentina, 5, 65-92.

Kraselsky, J. (2007). De las Juntas de Comercio al Consulado. Los comerciantes rioplatenses y sus estrategias corporativas, 1779-1794. Anuario de Estudios Americanos, 64, serie 2, 167.

Kraselsky, J. (2010). Manuel Belgrano y su fidelidad a la Corona: entre la autonomía y la Independencia. En G. Paz (coord.), Desde este día en adelante; Revolución. Testimonios de 25 de mayo (pp.131-144). Buenos Aires: Eudeba,.

Kraselsky, J. (2011). Las estrategias de los actores del Río de la Plata: Las Juntas y el Consulado de Comercio de Buenos Aires a fines del Antiguo Régimen, 1748-1809 (Tesis de Doctorado). Memoria Académica Universidad Nacional de La Plata, Facultad de Humanidades y Ciencias de la Educación.

Lafit, F. (2017). Ilustración española y economía política en la prensa rioplatense tardocolonial. Anuario del Instituto de Historia Argentina, 17(1), 1-19.

Laserna Gaitán, A. (1995). La crisis de la élite mercantil limeña y la prohibición de comercio a los productos británicos en 1780. Chronica Nova, 22, 165-184.

Lémperière, A. (2008). Los hombres de letras hispanoamericanos y el proceso de secularización (1800-1850). En C. Altamirano y J. Myers (dir.) (2008), Historia de los intelectuales en América Latina. Tomo 1. La ciudad letrada de la conquista al modernismo (pp. 242-268). Buenos Aires: Katz Editores,.

Llombart Rosa, V. (2006). Economía política y reforma en la Europa mediterránea del siglo XVIII: una perspectiva española. Cajamar, Mediterráneo económico, Caja Rural Intermediterránea, 9, 95-113.

Martínez, P. (2009). El pensamiento agrario ilustrado en el Río de la Plata: un estudio del Semanario de Agricultura, Industria y Comercio (1802-1807). Mundo Agrario: Revista de estudios rurales, 9(18), 1-33.

Mazzeo, C. (2012). Gremios mercantiles en las guerras de independencia. Perú y México en la transición de la colonia a la República, 1740-1840. Lima: Instituto de Estudios Peruanos, Banco Central de Reserva del Perú.

Milano, A. (2017). Regeneración, economía política y educación en la monarquía española del siglo XVIII. Conceptos en la delimitación de un campo semántico. Cuadernos Dieciochistas, 18, 367-405.

Moutoukias, Z. (1988). Contrabando y Control Colonial en el Siglo XVII: Buenos Aires, el Atlántico y el Espacio Peruano. Buenos Aires: Centro Editor de América Latina S.A.

Moutoukias, Z. (1992). Réseaux personnels et autorité coloniale : les négociants de Buenos Aires au XVIIIe siècle. Annales. Économies, Sociétés, Civilisations, 47\# année, 4-5, 889-915.

Moutoukias, Z. (1995). El crecimiento en una economía colonial de antiguo régimen. Reformismo y sector externo en el Río de la Plata (1760-1796). Arquivos do Centro Cultural Calouste Gulbenkian, 34, 771-813.

Myers, J. (1998).La cultura literaria del período rivadaviano: saber ilustrado y discurso republicano. En F. Aliata y M. Munilla Lacasa, (eds.), Carlos Zucchi y el neoclasicismo en el Rio de la Plata (pp.131-148). Buenos Aires: Eudeba/ Instituto Italiano de Cultura de Buenos Aires.

Navallo, T. (2010). Ideas Ilustradas en el Río de la Plata de los manuscritos al Proyecto Geográfico en el Telégrafo Mercantil (1801-1802). Tinkuy: Boletín de investigación y debate, 14, 165. https://dialnet.unirioja.es/servlet/r evista?codigo $=13871$

Navarro Floria, P. (1987). Notas para un estudio del ideario económico y político de Manuel Belgrano. Quinto Centenario, 13, 173-197.

Pastore, R., y Calvo, N. (2000). Cultura colonial, ideas económicas y formación superior "ilustrada" en el Río de la Plata. El caso de Manuel Belgrano. Prohistoria, 4, 2000, 27-58.

Piqueras Haba, J. (1991). El fomento de plantas textiles en la España ilustrada: Una visión espacial. Cuadernos de geografia, 50, 247-262. 
Portillo Valdés, J. M. (2009). Victorián de Villava, fiscal de Charcas; reforma de España y nueva moral imperial. Studia histórica. Historia contemporánea, 27, 27-52.

Rodríguez de Campomanes, P. (1775). Discurso sobre la educación popular de los artesanos y su fomento. Madrid: Imprenta de Antonio Sancho.

Rodríguez, B. (2013). Una justicia corporativa: Saberes, prácticas y estrategias judiciales hacia el interior del Tribunal del Consulado de Buenos Aires (1794-1821). Anuario del Instituto de Historia Argentina, 13, 9.

Ruibal, B. (2000). Cultura y política en una sociedad de Antiguo Régimen. En E. Tandeter (coord.), Nueva Histora Argentina, tomo 2 (p. 430). Buenos Aires: Sudamericana.

Sánchez Léon, P. (2005). Ordenar la civilización: semántica del concepto de Policía en los orígenes de la Ilustración española. Política y sociedad, 42(3), 139-156.

Santilli, D. (2013). ¿Perjudiciales o beneficiosas? La discusión sobre el impacto económico de las reformas borbónicas en Buenos Aires y su entorno. Fronteras de la historia, 18(2), 247-283.

Schlez, M. (2016). ¿Esclavistas versus monopolistas? Las disputas en torno al tráfico de esclavos en el virreinato rioplatense (1780-1810). Boletin Americanista, 72, 133-154.

Siegrist, N. (2006). La hidalguía en Buenos Aires en el siglo XVIII. Conceptos sobre su alcance en los actos positivos, Procesos Históricos. Revista semestral de historia, arte y ciencias sociales, 9, 7.

Socolow, S. (1991). Los mercaderes del Buenos Aires Virreinal: familia y comercio. Buenos Aires: Ediciones de La Flor.

Souto Mantecón, M. (1990). Los consulados de comercio en Castilla e Indias. Su establecimiento y renovación (1494-1795). Anuario de Historia del Derecho, 2, 227-250. https://dialnet.unirioja.es/servlet/revista?codigo=4 629

Street, D. (1988). Jovellanos, an Antecedent to Modern Human Capital Theory. History of Political Economy. Duke University Press, 20(2), 191-206.

Suárez, T., y Tornay M. (2003). Anuario de estudios americanos, 60(2), 521-555.

Tavárez Simó, F. (2015). La invención de un imperio comercial hispánico, 1740-1765. Magallánica, Revista de Historia Moderna, 3, 56-76.

Tjarks, G. (1962). El consulado de Buenos Aires y sus proyecciones en la historia del Río de la Plata. Buenos Aires: Universidad de Buenos Aires, Facultad de Filosofía y Letras, Instituto de Historia Argentina Dr. Emilio Ravignani.

Vaccani, M. (2015). Fiscalidad en el Antiguo Régimen. Indagaciones en torno a la estructura fiscal del Virreinato del Río de la Plata. El caso de la Real Aduana de Buenos Aires (1776-1810). En M. Sandrín y N. Biangardi (comps.), Los espacios portuarios: Un lugar de encuentro entre disciplinas (pp.268-283). Buenos Aires:Facultad de Humanidades y Ciencias de la Educación, Universidad Nacional de la Plata.

Wasserman, F. (2008). Liberal/Liberalismo. En N. Goldman (ed.), Lenguaje y revolución. Conceptos politicos clave en el Rio de la Plata, 1780-1850 (pp. 67-82). Buenos Aires: Prometeo.

Zamora, R. (2014). Sobre la función de policía y el orden económico en San Miguel de Tucumán a fines del siglo XVIII. De presuntos delincuentes, acaparadores y monopolistas. Historia y Memoria, 8, 175-207.

\section{Notas}

1 A modo de ejemplo Campomanes alude al menos 90 veces al concepto de ociosidad en una de sus obras; Arriquibar 30; Dánvila y Villarrasa en 15 oportunidades, al igual que Jovellanos en uno de sus escritos. (Campomanes, 1775; Arriquibar, 1779; Dánvila y Villarrasa, 1779; Jovellanos, 1797, Astigarraga y Usoz Otal, 2008)

2 El concepto patria propio del período colonial era el lugar, ciudad o país en que se había nacido; de allí que los miembros del Cabildo fuesen llamados "padres de la patria". No obstante, al constituir las bases del orden social el respeto por la religión, la fidelidad al rey y el patriotismo, esta tríada no determinaba claramente cuál era la patria: podía implicar el espacio virreinal, a la América española o a la monarquía toda. Por lo tanto, la patria en este sentido se entiende como la comunidad amplia en la que se vivía y el amor a esa patria era el compromiso con el orden y el bienestar general (Di Meglio, 2008). 
3 Archivo General de la República Argentina (1895). Libros del Consulado. Tomos III y IV. Adolfo Carranza (dir.). Buenos Aires: Imprenta Kraft. (En adelante AJGCBA), 14/10/1797, 18/11/1797, 4/12/1797, 8/03/1798, pp. 75: 86; 99; 145. Otros puntos tratados fueron el cobro de derechos en La Paz a las harinas; irregularidades en el cobro de alcabalas en Oruro y pago de derechos de avería al Consulado por tráfico de esclavos. Véase AJGCBA, 16/03/1798, 13/04/1798, 14/07/1798, pp. 147; 158; 196.

4 AJGCBA, 14/02/1798, p. 135.

5 AJGCBA, 13/09/97, 14/12/1797, 6/09/1798, pp. 67; 101; 220.

6 AJGCBA, 17/07/1797, 21/04/1798, 27/08/1798, p. 35; 41; 161.

7 AJGCBA, 22/12/1798, p. 282.

8 AJGCBA, 15/01/1798, p. 113;20/01/98 p. 116;01/02/98, p. 122.

9 AJGCBA, 27/06/1798, p. 188; 31/08/1798.

10 AJGCBA, 15/10/1798, pp. 232.

11 AJGCBA, 11/12/1794 pp. 3-7.

12 AJGCBA, 28/11/1797 pp. 89-90.

13 Tal el caso por ejemplo del pedido de Pedro Duval de Barragán para el desembarco de esclavos que conducía con su zumaca desde Pernambuco. AJGCBA, 30/01/1798 pp. 119.

14 AJGCBA, 10/02/1798 pp. 129-132.

15 AJGCBA, 5/02/1798 pp. 125.

16 AJGCBA, 30/10/1797, p. 82; 28/03/1798, p. 153; 13/04/1798, p. 157; 27/08/1798, p. 212; 18/08/1798, p. 216.

17 AJGCBA, 13/03/1797, pp. 7-29.

18 AJGCBA, 13/03/1797, pp. 30-33.

19 AJGCBA, 14/08/1798, p. 213; 14/11/1798, p. 256.

20 Refería a la real orden del 18 de noviembre de 1797. AJGCBA, 3/11/1798, p. 242.

21 Si bien excede el propósito de este trabajo, es destacable la presencia del término "colonia" en el plano discursivo de las actas consultadas. Si se considera la perspectiva que considera la intención de la monarquía española de convertirse en un imperio comercial que encauzara a sus dominios como colonias para propiciar su beneficio, como importadoras de productos elaborados en la Península y exportadoras de frutos coloniales (Tavárez Simó, 2015), el uso del vocablo colonia por parte de los consiliarios podría indicar una inclinación en igual sentido.

22 AJGCBA, 3/11/1798, pp. 243-254.

23 AJGCBA, 03/11/1798, p. 241.

24 AJGCBA, 30/10/1799, tomo 4, pp. 117- 119.

25 AJGCBA, tomo 4, p. 167.

26 AJGCBA, 3/11/1798, p. 169.

27 AJGCBA, 30/09/1797 p. 73.

28 Las niñas premiadas fueron María de Jesús y Eugenia López; sus hilazas fueron guardadas como constancia de su útil trabajo. AJGCBA, 14/10/1797 p. 76.

29 AJGCBA, 26/05/1798 p. 76.

30 AJGCBA, 17/07/1798 pp. 199-201.

31 AJGCBA, 18/11/1797 pp. 84-85.

32 AJGCBA, 8/03/1798, p. 144.

33 AJGCBA, 27/08/1798, p. 227.

34 AJGCBA, tomo 3, 27/08/1798, p. 212; tomo 4, 7/03/1799, p. 25; 34-36; 23/04/1799, pp. 45-48; 17/5/1799, pp. 52-53; 12/09/1799, p. 85; 5/10/1799, p. 110.

35 AJGCBA, 17/12/1799, tomo 4, p. 144. 